\title{
Umbilical Reconstruction as an Adjuvant Procedure After Umbilical Hernia Repair or Midline Abdominal Incision
}

\author{
Emad K. Bayumi \\ Crimean Medical Academy Named After S.I. Georgievsky, Crimean Federal University Named After V.I. Vernadsk, Crimea, Russia
}

Email address:

Emadsurg666@hotmail.com

To cite this article:

Emad K. Bayumi. Umbilical Reconstruction as an Adjuvant Procedure After Umbilical Hernia Repair or Midline Abdominal Incision. Journal of Surgery. Special Issue: Gastrointestinal Surgery: Recent Trends. Vol. 4, No. 2-1, 2016, pp. 31-35. doi: 10.11648/j.js.s.2016040201.17

\begin{abstract}
Introduction: Umbilicus construction is usually needed post umbilical or Para umbilical hernia repair and in some techniques the umbilicus needs reconstruction after exploratory laparotomy. There are many techniques for umbilical reconstruction and the common objective of all these techniques is to mention umbilicus that looks natural in terms of location, size and depth. And avoid ischemic necrosis of the edges of the umbilicus flap. The author in this study described a new and simple technique for umbilical reconstruction. Patients and methods: The present study included 50 cases who were subjected to anterior abdominal wall incision (umbilical, Para umbilical or midline incision) Crimean Medical Academy named after S.I. Georgievsky Crimean Federal University named after V.I. Vernadsk Russia in department of general and gastrointestinal surgery. The study started from January 2012 to may 2015. End points: The primary end point of the study was the aesthetic appearance of the new umbilicus and the second end point was patient satisfaction of the operative outcome. Results: Over 50 cases of midline abdominal incision we performed reconstruction of the umbilicus with a new and simple technique. There were 40 females and 10 males with age ranging from 28 to 52 years with the mean value as $40 \pm 7.35$ years. Conclusion: The technique for reconstruction of the umbilicus presented in the present study is a simple technique without complications, with long term success and good aesthetic appearance. The new constructed umbilicus exhibits appropriate features of both depth and size and avoids the appearance of scarring and secondary stenosis or necrosis.
\end{abstract}

Keywords: Umbilical Reconstruction, Midline Incision, New Technique

\section{Introduction}

The umbilicus is an important and essential aesthetic component in the abdomen and it is a centrally placed depressed scar surrounded by skin folds, forming superior hood. The shape of the umbilicus is elliptical in vertical direction or T-shaped with the long axis lying vertically in the mid-line [1]. Reconstruction of a destroyed umbilicus after umbilical herniorrhaphy was first reported by Mc Millan in 1955 [1, 2]. The aesthetic outcome of the umbilicus is often affected by improper positioning by low placement or shallow, flat appearance in the late postoperative period. Disappointing positioning and shape of the umbilicus, along with periumbilical scarring, are the usual drawbacks of abdominoplasty $[2,3]$. There are many techniques for umbilical reconstruction and the common objective of all these techniques is to create a new umbilicus that looks natural in terms of location, size and depth [1-6]. The author in this study described a new and simple technique for umbilical reconstruction.

\section{Patients and Methods}

\subsection{Patients}

The present study included 50 cases who were subjected to large para umbilical hernia repair and midline exploratory incision in Crimean Medical Academy named after S.I. Georgievsky Crimean Federal University named after V.I. Vernadsk Russia in department of general and gastrointestinal surgery. The study started from January 2013 to May 2015. Written consents were obtained from all patients before the study. The steps of operative interferences were explained to all patients. The local ethics committee had approved all operative procedures. Ethical approval for this study department of general and gastrointestinal surgery Crimean Medical Academy named after S.I. Georgievsky Crimean Federal University named after V. I. Vernadsk Russia. 


\subsection{Operative Techniques}

Midline incisions were designed to cover the hernia defects then upon reaching the umbilicus, two trianglular incisions were performed around umbilicus then extending the incision to the lower abdomen according to the need \{Figure 1a and $1 b$. Repair of the proper para umbilical hernia was performed using mesh prothesis as previously reported [8]. The skin flap of the umbilicus was trimmed and fashioned by excision of the thin, stritched skin \{Figure 2\}. The refashioned neo umbilicus was fixed by three proline stitches deep to the rectus sheath \{Figure $3 \mathrm{a}\}$. Then, completion of closure of skin incision was performed using vicryl $2 / 0$ as subcuticular sutures with suction drain \{Figure $3 b$ \}. All patients were followed up for postoperative wound care and aesthetic outcome \{Figure 4 \}.
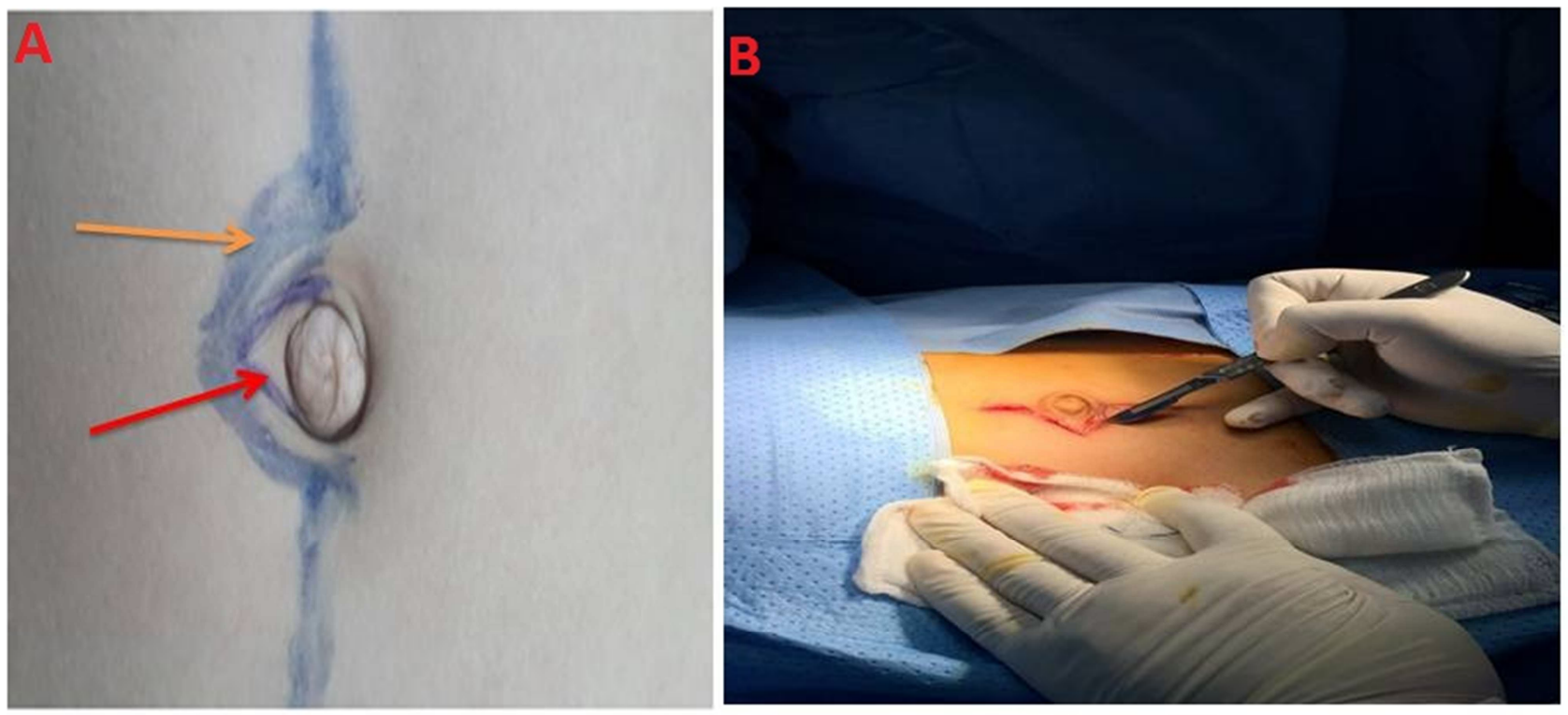

Figure 1. A preoperative photograph of patient with paraumbilical hernia showing skin marking with two triangles around the umbilicus denoted by the two arrows [A]. In [B], an intraoperative photograph of patient with paraumbilical hernia. A medline incision with trianglular shaped extension over the umbilicus was started.

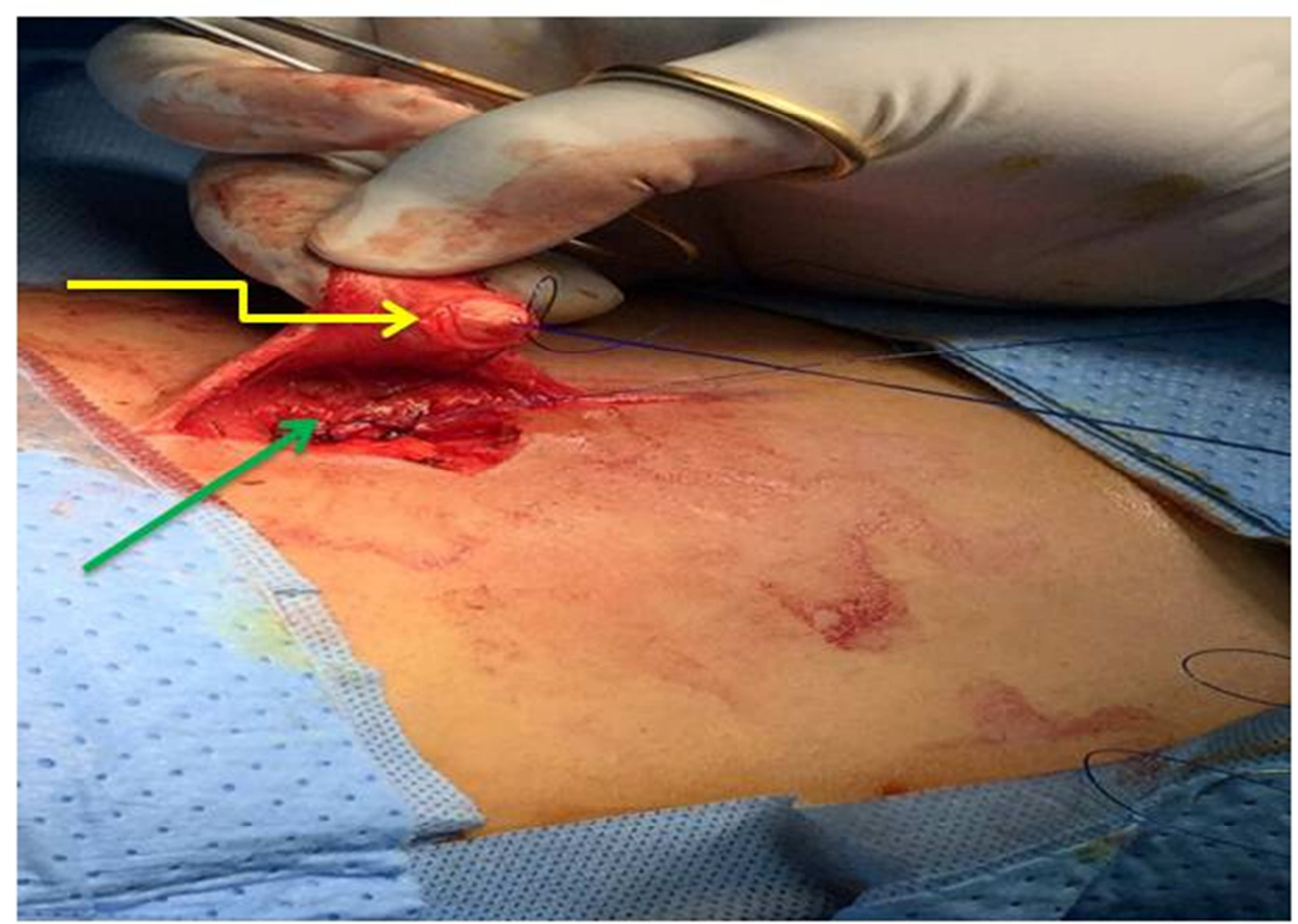

Figure 2. An intraoperative photograph of patient with paraumbalical hernia showing repair of the hernia as indicated by green arrow. The yellow arrow denotes the trimmed skin over the umbilicus. 

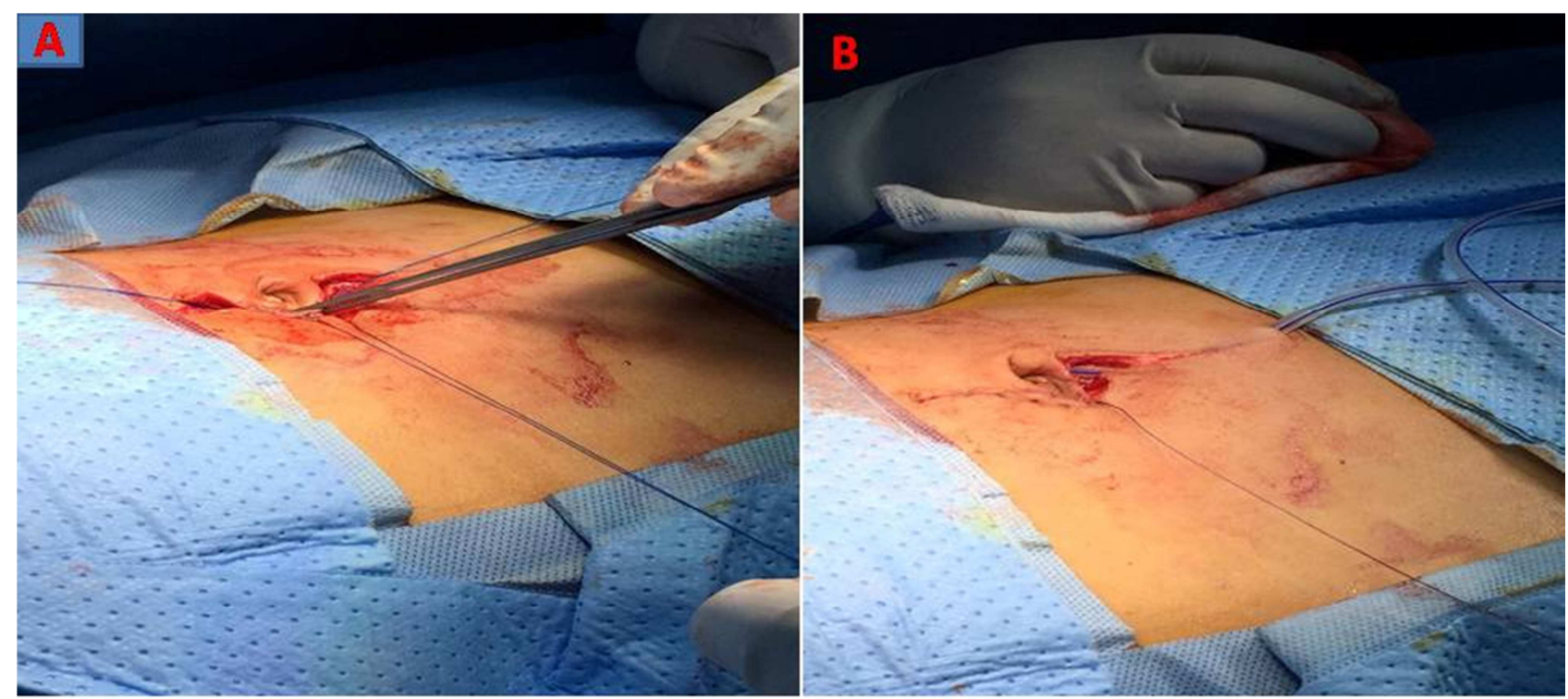

Figure 3. An intraoperative photograph of patient with paraumbilical hernia showing the three umbilicus stitches performed for fixation of the neoumbilicus [A] and in $[B]$, the skin closure is nearly finished.

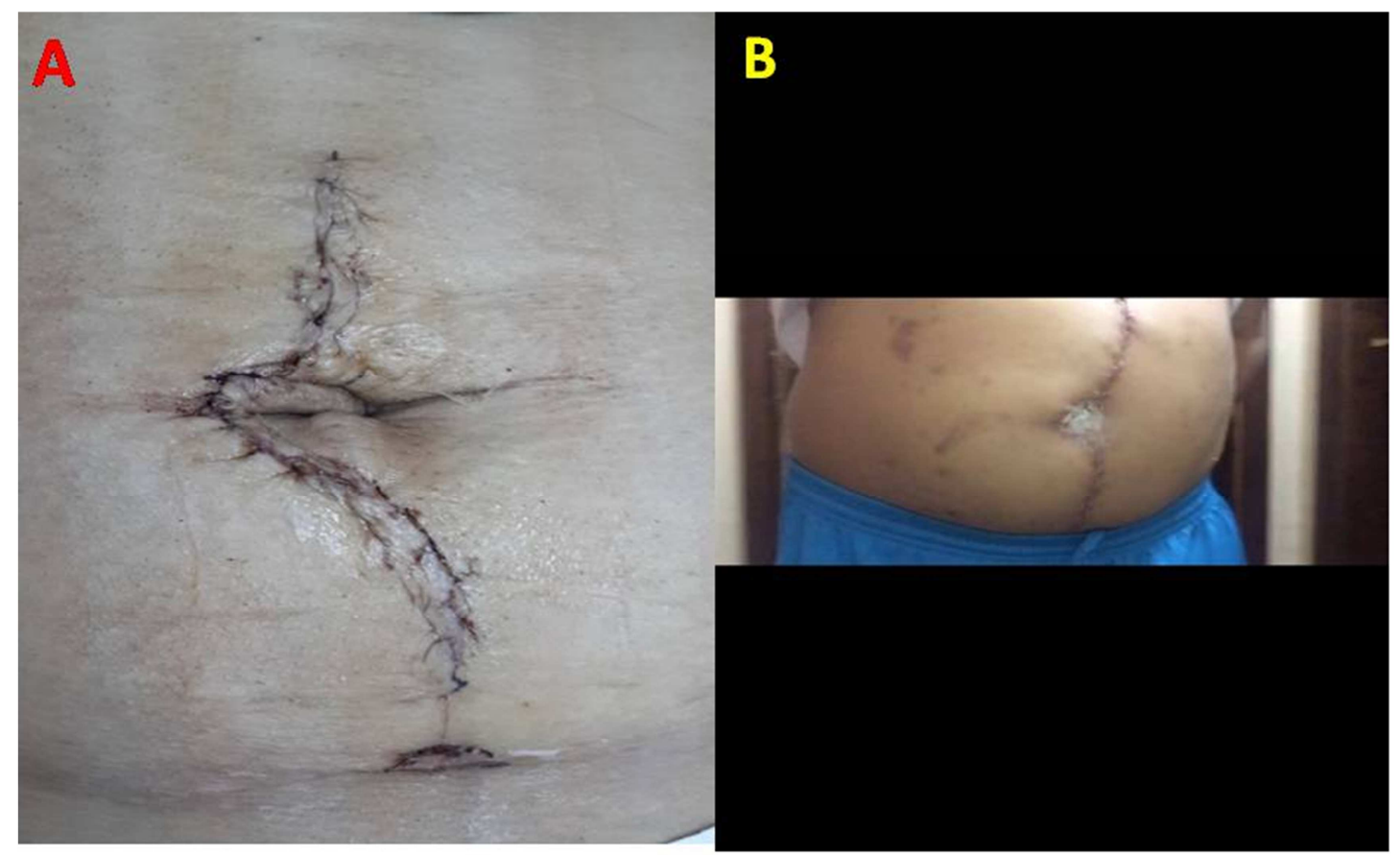

Figure 4. A two-week postoperative photograph showing the neoumbilicus in position [A] and after two months [B].

\subsection{End Points}

The primary end point of the study was the aesthetic appearance of the new umbilicus and the second end point was patient satisfaction of the operative outcome.

\section{Results}

Over 50 cases of Medline abdominal incision was performed reconstruction of the umbilicus with a new and simple technique. There were 30 females and 20 males with age ranging from 28 to 58 years with the mean value as $40 \pm$ 7.35 years.

Table 1. Showing our patients as regard their age and body mass index (BMI).

\begin{tabular}{llll}
\hline Item & & Male $\{\mathbf{N}=\mathbf{2 0}\}$ & Female $\{\mathbf{N}=\mathbf{3 0}\}$ \\
\hline \multirow{2}{*}{ Age } & Age $<50$ & 10 & 19 \\
& Age $>50$ & 10 & 11 \\
& BMI $<25$ & 6 & 7 \\
BMI & BMI $<30$ & 8 & 12 \\
& BMI $>30$ & 6 & 11 \\
\hline
\end{tabular}

The size of hernia defect was seen in table 2 where the value mentioned is the longest measurement. 
Table 2. The size of hernia defect in our patients.

\begin{tabular}{lll}
\hline Defect & Male $\{\mathbf{N}=\mathbf{2 0}\}$ & Female $\{\mathbf{N}=\mathbf{3 0}\}$ \\
\hline Small $=3 \mathrm{~cm}$ & 6 & 8 \\
Medium $=5 \mathrm{~cm}$ & 9 & 12 \\
Large $\geq 5 \mathrm{~cm}$ & 5 & 10 \\
\hline
\end{tabular}

\section{Discussion}

Reconstruction of the umbilicus is a procedure that refines the outcomes of abdominal surgery and its absence significantly affects the aesthetics of the abdomen, making it an essential part of the anatomy. The aesthetic appeal of the abdomen is directly related to good umbilical conformation [7]. The absence or disfigurement of the umbilicus is both cosmetically and psychologically distressing to patients and the goal of aesthetically pleasing umbilical reconstruction is to create a neo umbilicus with sufficient depth, good morphology, with natural-looking superior hooding and minimal scarring [9]. In our study, umbilical reconstruction was performed in ventral herniorhaphy and laparotomy and in deformed umbilicus due to paraumbilical hernias. There are different techniques for reconstruction of the new umbilicus after laparotomy and following large para umbilical hernia surgery [4]. Neoumbilicoplasty can be performed by lateral skin excisions and a rotation of two small para median flaps, by designing two flaps with V-Y advancement or by creating three simple triangular flaps and suturing their apices after defatting the skin flaps to the muscular plane [1]. Despite our technique for neoumbilicus reconstruction is so simple, the techniques described above are either unsatisfactory or too complex [10-12]. An elliptical skin island with fat excisions underneath and depression created through a purse string suture was reported by Marconi [13]. However, this technique requires thorough wound care for an extended period, as it leaves an open wound after the procedure [14] while our new technique required no additional wound dressing or care. A simple technique of using the purse string suture to reconstruct the inner walls of neoumbilicus was reported with satisfying results [15]. A new scarlessumbilicoplasty technique, which bears many of the characteristics of an ideal needs; it is easy to perform and results in the complete absence of visible scars and with a preferred vertical orientation [16-18]. Also new umbilicus described in my previous study post abdominoplasty and forming new umbilicus but in this study [19]. In this study technique, we performed the neo umbilical construction after making longitudinal incision and triangles to decrease the width of the umbilicus to keep more vascular flap and 3 stitches made dawn surface in the umbilicus make inverted cosmetic umbilicus and the longitudinal incision make easy repair for divarication of recti and also easy access for repair of combined medline hernias of, also no complex flaps or visible scars.

\section{Conclusion}

The technique for reconstruction of the umbilicus presented in the present study is a simple technique without complications, with long term success and good aesthetic appearance. The new constructed umbilicus exhibits appropriate features of both depth and size and avoids the ischemia of the edges.

\section{References}

[1] Al-shaham AA. Neoumbilicoplasty is a useful adjuvant procedure in Abdominoplasty. Can J Plast Surg. 2009 Winter; 17(4): e20-e23.

[2] Bartsich SA, Schwartz MH. Purse-string method for immediate umbilical reconstruction. Plast Reconstr Surg J. 2003; 112: $1652-5$.

[3] Santanelli F, Mazzocchi M, Renzi L, Cigna E. Reconstruction of a natural-looking umbilicus. Scand J Plast Reconstr Surg Hand Surg. 2002; 36: 183-5.

[4] Morshed G. A Simple New Technique for Neo-Umbilicoplasty. Med. J. Cairo Univ., 2012, 80(1): 759-761.

[5] Yotsuyanagi T, Nihei Y, Sawada Y. A simple technique for reconstruction of the umbilicus, using two twisted flaps. Plast Reconstr Surg J. 1998; 102: 2444.

[6] Abenavoli FM, Cusano V, Cucchiara V, et al. An idea for umbilicus reconstruction. Ann Plast Surg J.2001; 46: 194.

[7] Iida N, Ohsumi N. Reconstruction of umbilical hypogenesis accompanied by a longitudinal scar. Plast Reconstr Surg 2003; 111: $322-5$.

[8] Saber A, Bayumi EK, Onlay versus Sublay Mesh Repair for Ventral Hernia, Journal of Surgery. Special Issue: Abdominal Surgery: Toward the Best. 2016; 4, (1-1): 1-4.

[9] Lee YT, Kwon C, Rhee SC, Cho SH, Eo SR. Four flaps technique for neoumbilicoplasty. Arch Plast Surg. 2015 May; 42(3): 351-5.

[10] Hong YG, Cho JJ. Reconstruction of scarred umbilicus using an inverted c-v flap: a case report. J Korean Soc Plast Reconstr Surg. 2007; 34: 653-655.

[11] Donnabella A. Anatomical reconstruction of the umbilicus. Rev. Bras. Cir. Plást. 2013, 28 (1): Jan./Mar. 119-123.

[12] IIDA N. and OHSUMI N.: Reconstruction of umbilical hypogenesis accompanied by a longitudinal scar. Plast. Reconstr. Surg., 2003; 111: 322-5.

[13] Pfulg M, Van de Sijpe K, Blondeel P. A simple new techniquefor neo-umbilicoplasty. Br J Plast Surg. 2005; 58: 688-691.

[14] Marconi F. Reconstruction of the umbilicus: A simple technique. Plast Reconstr Surg J. 1995; 95: 1115.

[15] Bartsich SA, Schwartz MH. Purse-string method for immediate umbilical reconstruction. Plast Reconstr Surg. 2003; 112: $1652-1655$.

[16] Kirianoff TG. Making a new umbilicus when none exists. Plast Reconstr Surg J. 1978; 61: 603.

[17] Pardo Mateu L, Chamorro Hernandez JJ. Neoumbilicoplasty Through a Purse-String Suture of Three Defatted Flaps. Aesthetic Plast Surg. 1997 Sep-Oct; 21(5): 349-51. 
[18] Bruekers SE1, van der Lei B, Tan TL, Luijendijk RW, Stevens HP. "Scarless" umbilicoplasty: a new umbilicoplasty technique and a review of the English language literature. Ann Plast Surg. $2009 \mathrm{Jul} ; 63(1)$ : 15-20.
[19] Bayumi EK. Neoumbilical Reconstruction as an Adjuvant Procedure in Abdominoplasty Journal of Surgery2016; 4(1-1): 16-18 Published online September 16, 2015. 